\title{
A TEMÁTICA CULTURA ORGANIZACIONAL NOS ESTUDOS NA ÁREA DA SAÚDE E DA ENFERMAGEM ${ }^{1}$
}

\author{
Marisa Antonini Ribeiro Bastos ${ }^{2}$
}

Bastos MAR. A temática cultura organizacional nos estudos na área da saúde e da enfermagem. Rev Latino-am Enfermagem 2001 julho; 9(4):68-74.

O objetivo deste artigo é apresentar uma revisão da literatura sobre a temática cultura organizacional apontando os pressupostos subjacentes às diferentes concepções teórico-metodológicas. Focaliza os estudos na área da saúde a da enfermagem.

PALAVRAS CHAVE: administração, cultura organizacional

\section{ORGANIZATIONAL CULTURE IN HEALTH AND NURSING STUDIES}

This study aims at presenting a literature review on the theme concerning organizational culture and at pointing out the subjacent assumptions to some theoretical and methodological conceptions. It focuses on health care and nursing studies.

KEY WORDS: administration, organizational culture

\section{LA TEMATICA “CULTURA ORGANIZACIONAL” EN LOS ESTUDIOS DEL ÁREA DE LA SALUD Y DE LA ENFERMERÍA}

El objetivo de este artículo es presentar una revisión de la literatura sobre la temática "cultura organizacional" señalando los presupuestos subyacentes en las diferentes concepciones teórico-metodológicas. Centra los estudios en el área de la salud y de la enfermería.

PALABRAS CLAVES: administración, cultura organizacional

\footnotetext{
${ }^{1}$ Projeto financiado pela FAPEMIG; ${ }^{2}$ Doutor, Professor Adjunto do Departamento de Enfermagem Básica da Escola de Enfemagem da UFMG, e-mail: marisa@dourado.enf.ufmg.br
} 


\section{INTRODUÇÃO}

\section{$T$ endo em vista a crescente incorporação das abordagens} interpretativas nos estudos organizacionais, necessário se faz examinar, cuidadosamente, a terminologia utilizada ${ }^{(1)}$, bem como explicitar os pressupostos subjacentes às perspectivas adotadas.

Assim, a opção por estudar um fenômeno cultural organizacional requer um posicionamento frente aos diferentes pressupostos epistemológicos subjacentes às correntes da Sociologia e da Antropologia contemporânea que norteiam os estudos organizacionais. Implica, também, numa discussão sobre a natureza da abordagem metodológica adotada.

Na literatura sobre a temática Cultura Organizacional são identificadas diferentes perspectivas epistemológicas e metodológicas. Diante dessa diversidade de abordagens, vários autores tem investido em tentativas classificatórias.

Este artigo tem o objetivo de subsidiar a reflexão sobre as diferentes concepções teórico-metodológicas que permeiam os estudos relacionados a temática Cultura Organizacional.

\section{A DIMENSÃO ANTROPOLÓGICA DA ORGANIZAÇÃO}

A Teoria Organizacional, a partir de 1979, direciona o modelo das organizações enquanto sistema aberto para o modelo cultural embora ainda hoje exista uma predominância de estudos com o primeiro enfoque ${ }^{(2)}$.

Após 1980 há uma mudança no estilo e conteúdo das publicações, congressos, seminários e conferências sobre a temática ${ }^{(3-4)}$, quando abre-se "espaço para as metodologias qualitativas, para o interacionismo simbólico e para a etnometodologia aplicada às organizações" ${ }^{\prime \prime(3)}$.

Autora citada em grande parte dos estudos que buscam compreender os fenômenos culturais das organizações, também caracteriza as diferentes posturas teórico-metodológicas de acordo com as diferentes concepções dos termos cultura e organização ${ }^{(2)}$.

Com base nos pressupostos subjacentes aos diferentes conceitos de cultura e organização, são identificadas cinco tendências na literatura sobre cultura organizacional, classificadas nas seguintes áreas temáticas: Administração Comparativa ou Transcultural, Cultura Corporativa, Cognição Organizacional, Simbolismo Organizacional e Processos Inconscientes e Organizações ${ }^{(2)}$.

As características de cada uma das tendências foram sintetizadas e estão relacionadas no Quadro 1.

O desenvolvimento da teoria e da prática administrativa deu origem a uma variedade de concepções sobre os termos ${ }^{(2)}$. No que se refere ao termo organização, as metáforas de máquina ou organismo são mais freqüentemente usadas. A metáfora mecânica é a imagem da organização como "instrumento para realizar uma tarefa", com múltiplas partes projetadas para funcionar com eficiência.

Quadro 1- Características teórico-metodológicas das cinco tendências de pesquisa sobre cultura organizacional ${ }^{(2)}$

\begin{tabular}{|c|c|}
\hline TENDÊNCIAS & CARACTERISTICAS \\
\hline $\begin{array}{l}\text { ADKANISTRAÇÃO } \\
\text { COHPARATIYA OU } \\
\text { TRANSCULTURAL }\end{array}$ & 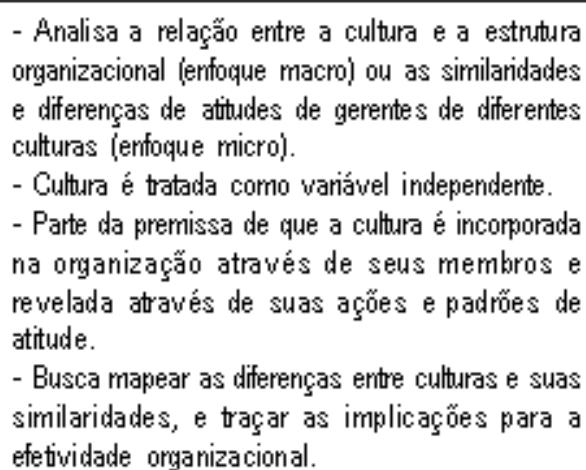 \\
\hline
\end{tabular}

CULTURA - Cultura é tratada como varível intema.

COPPORATIV - Parte da premissa de que organizaçốes sẫo produtoras de cultura (intuais, lendas e cerimônias) - Ênfase nas qualidades socio-culturais desenvolvidas dentro da organizaçẫo.

- Referencial na teoria de Sistemas. Concepçẫo de que a cultura contribui para o equilibrio sistêmico geral e a efetividade organizacional.

- Concepçẫo dos trabalhos de Desenvolvimento e Mudança organizacional.

COGNIÇão - Cultura é tratada como conhecimentos ORGAAIZACIONAL comparthados ou um sistema de conhecimentos e crenças.

- A cultura organizacional pode ser representada através do "master contract" que se desenvolve a partir das interaçỗes interpessoais, incluindo a autoimagem da organizaçẫo, suas regras construtivas e reguladoras.

- Busca compreender as interaçốes sociais, suas regras sob o ponto de vista dos seus membros, com 0 objetivo de intervençẫo organizacional.

SIKBOLISHO - Cultura tatada como um sistema de símbolos e ORGANIZACIONAL significados comparthados.

- Busca descrever os sistemas temáticos de significados subjacentes às atividades (temas de cultura) com o objetivo de decifrátos e compreendêlos.

- Os temas (expressôes de várias modalidades simbólicas) representam o cerne da análise simbólica de uma organizaçã̃o como cultura.

- Ênfase no ponto de vista dos informantes, ou seja, como os membros da organizaçã̃o interpretam e compreendem suas experiências e como suas interpretaçốes e compreensôes se relacionam às açốes.

PROCESSOS - Cultura é tratada como uma manifestação e INCONSCIENTESE expressẫo de operaçốes inconscientes da mente. ORGAHIZAÇÖES - Referencial na antropologia estrutural de LeviStruss. 
A metáfora da organização como um organismo é a imagem da organização "lutando para a sobrevivência dentro de um ambiente em mudança"(3). Na ótica da autora as metáforas - organismo e máquina são imagens do mundo físico e, historicamente, dominantes. Outras metáforas se referem ao mundo social, onde a organização é investigada enquanto um fenômeno social ${ }^{(5-7)}$.

No que se refere à maneira como o termo cultura tem sido tratado nos estudos organizacionais, podem ser identificadas duas vertentes básicas ${ }^{(2)}$. Numa vertente estão os trabalhos que tratam a cultura como algo que a organização tem. Assim sendo, a cultura é adotada como uma variável (dependente ou independente, interna ou externa). Numa outra vertente estão os estudos que tratam a cultura como um fenômeno que a organização é, ou seja, a cultura enquanto uma raiz metafórica da organização ${ }^{(2)}$. E seguir uma dessas duas vertentes significa adotar estratégias metodológicas diferentes, embora não incompatíveis ${ }^{(3)}$.

$\mathrm{Na}$ Figura 1 estão apresentados alguns aspectos relacionados às concepções de cultura e organização nas tendências de pesquisa ${ }^{(2)}$.

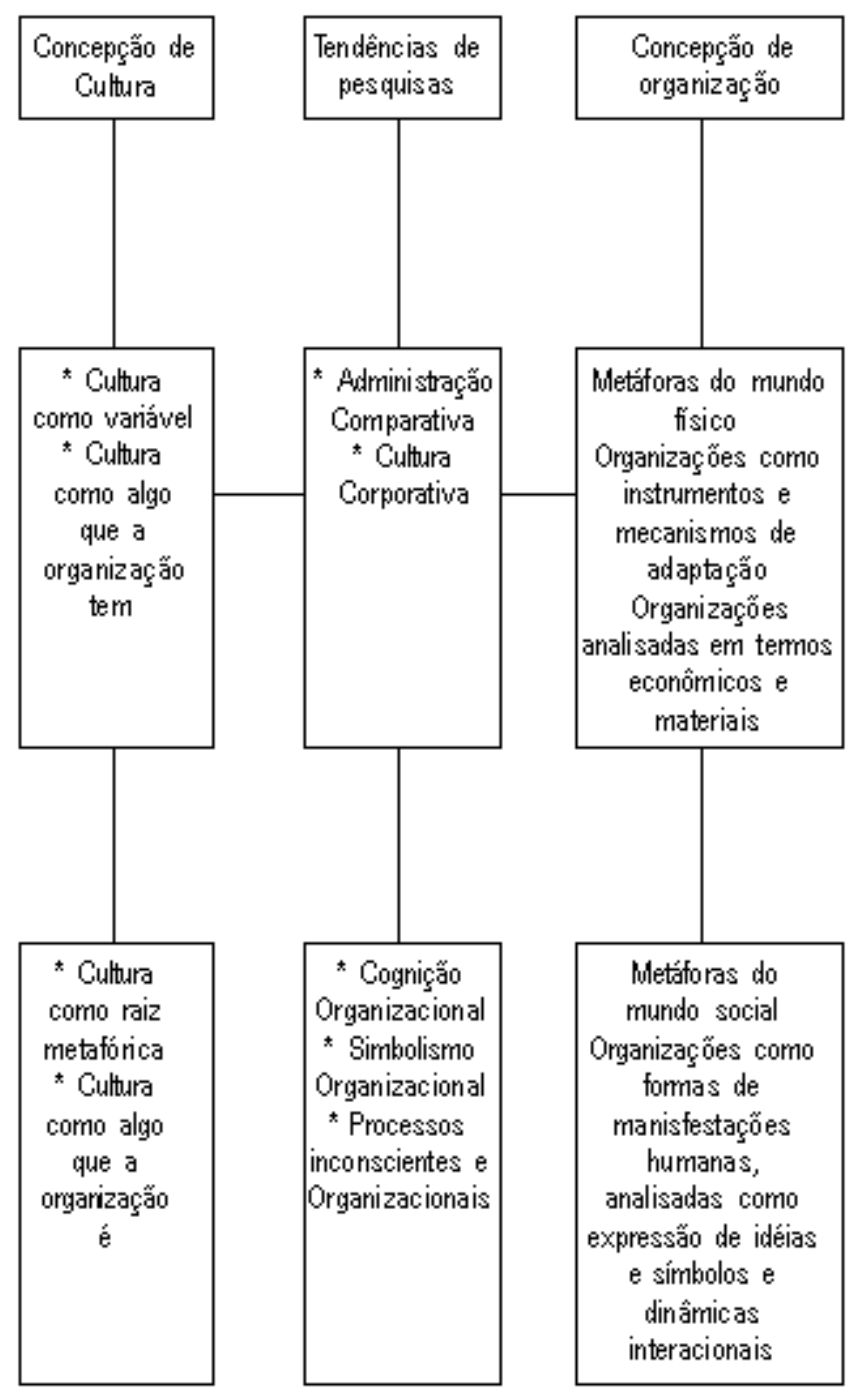

Figura 1 - Concepções de cultura e organização(2)
Assim, a interação dos conceitos de cultura e organização é evidente nas cinco vertentes de pesquisa organizacional e administrativa e envolve diferentes pressupostos relativos às concepções destes dois termos. As diferentes concepções destes termos são uma conseqüência das diferentes visões de mundo dos pesquisadores que são guiados por diferentes metáforas e buscam diferentes fins ${ }^{(2)}$.

No Quadro 2 estão representados os conceitos de cultura e organização, bem como as diferentes linhas da Antropologia e Teoria Organizacional que norteiam os aspectos teórico-metodológicos adotados pelos autores ${ }^{(2)}$.

Quadro 2 - Conceitos de cultura e organização

\begin{tabular}{|c|c|c|}
\hline $\begin{array}{l}\text { Conceitos de Cultura } \\
\text { na Antropologia }\end{array}$ & $\begin{array}{l}\text { Topicos na Pesquisa } \\
\text { Organizacional e } \\
\text { Administrativa }\end{array}$ & $\begin{array}{l}\text { Conceitos de Organi- } \\
\text { zação na Teoria das } \\
\text { Organizaçōes }\end{array}$ \\
\hline
\end{tabular}

Cultura é um instrumento "Cross-culture" ou Organizaçốes sấo insa serviço das neces- Administração com- tumentos sociais para sidades biológicas e parativa realização de tarefas.

psicológicas do homem. Ex.: Teoria Clássica da Ex: FuncionalismoHalinouski

Administraçã̃o

Cultura funciona como Cultura Comorativa um mecanismo adapta-

Organizaçỗes sã̃o organismos adaptativos existentes nos processos de troca com 0 ambiente.

Ex.: Teoria Contingencial.

Ex: Funcionalismo-

Estrutural Radcliffe-

Brown

Cultura é um sistema de Cogniçẫo Organizacogniçốes compartilha- cional

das. A mente humana

gera a cultura pelo

significado de um

número finito de regras.

Ex: Etnociência-

Goodenough

Cultura é um sistema de Simbolismo organizasímbolos e significados cional

compartilhados. A açẫo

simbólica necessita ser

interpretada, lida e deci-

frada para ser entendida.

Ex: Antropologia

simbólica- Geertz

Orģanizaçốes sẫo sistemas de conhecimentos. A organizaçẫo repousa na rede de significados subjetivos que os membros organizacionais compartham. Ex.: Teoria da Cogniçẫo Organizacional

Organizaçỗes sẫo modelos de discursos simbólicos. A organizaçẫo é mantida através de formas simbólicas, tais como a linguagem que facilita compartilhar os significados e as realidades.

Ex.: Teoria do Simbolismo Organizacional.

Cultura é uma projeçã̃o Processos Inconscienda infraestrutura univer- tes e Organizaçốes sal da mente.

Ex: EstruturalismoLevi-Strauss

Formas e práticas organizacionais sẫo manifestaçốes de processos inconscientes.

Ex.: Teoria da Transformaçã̃o Organizacional.

Fonte: (Freitas, 1991, p. 3) - Adaptada de Linda Smircich. "Concepts of Culture and Organizational Analysis". Admin Sci Q, 28(3):342, Sept. 1983 
As diversas posturas teórico-metodológicas em estudos organizacionais, advêm das diferentes concepções do termo cultura organizacional, quando se coloca a seguinte indagação: "são as organizações uma cultura, ou possuem uma cultura?"(2-3).

"No primeiro caso, a cultura é entendida sob o ponto de vista das consciências individuais; significa, o conjunto de interpretações da realidade pelos indivíduos. Nessa abordagem que é a geralmente adotada pela Sociologia Interpretativa, supõe-se uma mistura entre os valores do pesquisador e o fenômeno observado. No segundo caso, a cultura organizacional é um fato social e como a estrutura e a tecnologia, independe da percepção dos indivíduos; portanto, deve ser estudada através de métodos rigorosos e de validação"(3).

O processo de descrever a cultura organizacional remete à discussão três pontos básicos ${ }^{(8)}$.

0 primeiro se refere às diferentes posturas teóricometodológicas adotadas pelos pesquisadores. Em se tratando de pesquisa de fenômenos culturais das organizações podem ser identificados três tipos de posturas: a postura empiricista, a postura do clínico e a postura do antropólogo ${ }^{(8)}$.

$O$ segundo se relaciona às propostas conceituais e às categorias de análise e o terceiro, aponta as diferentes técnicas de investigação derivadas das diferentes propostas teóricometodológicas.

A postura do investigador empiricista "pode ser caracterizada como a postura do fotógrafo da realidade social, o que, no limite, implica em considerar a sociedade como a somatória de indivíduos e a cultura como a somatória de opiniões e comportamentos individuais" ${ }^{\text {(8) }}$.

Os referenciais teóricos e categorias de análise adotados pelos investigadores empiricistas geram propostas mais simplistas onde a intenção é "aprender os padrões culturais de uma organização a partir da somatória de opiniões e percepção de seus membros". As técnicas de investigação adotadas são, portanto, técnicas de levantamento de opiniões, através de questionário e entrevistas estruturadas, numa abordagem eminentemente quantitativa ${ }^{(8)}$.

A postura do Clínico ou Terapeuta é caracterizada como a do pesquisador/consultor. $O$ tipo de pesquisa realizada surge em decorrência de demandas da própria organização, diferindo das investigações "de cunho mais acadêmico, cujo objetivo primordial é o avanço do conhecimento científico" ${ }^{\text {"(8). }}$. Nesta perspectiva de análise, segundo a autora ${ }^{(8)}$, podem ser situados trabalhos de consultoria de Shein* que advogam a postura clínica para o estudo dos fenômenos culturais da organização, tendo fortes raízes antropológicas e psicológicas $^{(9)}$.
Os autores que trabalham sob esta perspectiva adotam as abordagens qualitativas, utilizando entrevistas, observação participante e não participante, dinâmicas de grupo, jogos e simulações como técnicas de investigação( $0^{(8)}$.

A postura do antropólogo é aquela do investigador que busca o "significado de condutas, práticas e formas simbólicas" e que "de forma semelhante ao antropólogo que pesquisa as sociedades primitivas, penetra na vida organizacional ${ }^{(8)}$. Para tal, partem de conceitos advindos da antropologia e adotam a perspectiva etnográfica para descrição dos universos simbólicos organizacionais.

O uso do paradigma etnográfico pode gerar estudos de três estilos principais, ou seja, o estilo holístico, o comportamental e 0 simbólico ${ }^{(9)}$.

O estilo holístico é pautado na literatura antropológica de pelo menos duas vertentes opostas, ou seja, no configuracionismo ${ }^{(10-}$ ${ }^{11)}$ e no funcionalismo da Antropologia social britânica ${ }^{(12-13)}$.

O uso da etnografia no estilo comportamental da literatura antropológica, não tem a finalidade de descobrir significados. Ao invés disso, seu objetivo é buscar a relação entre diferentes padrões comportamentais em estudos comparativos transculturais e intraculturais. Seus principais adeptos pautam seus pressupostos na teoria psicanalítica de desenvolvimento da personalidade, na teoria da aprendizagem e na Antropologia Cultural.

A essência do estilo simbólico está na "busca do ponto de vista do nativo", ou seja, busca "ajudá-los a ter acesso ao mundo conceitual no qual eles vivem para que possa ser estabelecido um diálogo com eles"(9). Esse estilo se divide em duas orientações epistemológicas, ou seja, a denominada etnociência ${ }^{(14)}$ e a "descrição densa"(15).

Compreender a cultura organizacional pressupõe buscar alcançar a profundidade dos significados organizacionais. Significa realizar uma etnografia pautada no diálogo, na compreensão do outro, na sua visão de mundo, na sua cultura, numa relação de intersubjetividade.

A cultura deve ser compreendida na sua dimensão de historicidade. Isso implica que, a busca da compreensão dos universos simbólicos compartilhados entre os membros de uma organização remete ao resgate da trajetória histórica de sua construção ${ }^{(15-16)}$.

Dessa forma, ao descrever a cultura dos membros de uma organização, devem ser consideradas as múltiplas situações sociais vivenciadas por eles dentro de um contexto social particular, bem como aspectos históricos da criação e desenvolvimento dessa instituição.

Quando a perspectiva simbólica é aplicada à análise

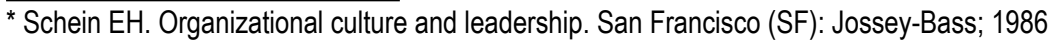


organizacional, a organização é compreendida como uma cultura, como um universo de símbolos e significados compartilhados. Alguns desses significados são expressos através da linguagem e muitos são "taken for granted" e expressos, indiretamente, através das ações. Os indivíduos usam desse sistema de significados para organizar pensamentos, entenderem uns aos outros e encontrar sentido no mundo que vivem. Esse mundo de significados constitui sua cultura ${ }^{(17)}$

A busca de temas é o cerne da análise simbólica de uma organização (Quadro 1). Ela é compreendida como uma forma de expressão e manifestação de interações humanas, peculiares entre seus membros.

\section{A CULTURA NAS INSTITUIÇÕES DE SAÚDE}

A análise das publicações nacionais sobre as instituições de saúde mostra que poucas obras tratam do tema - cultura organizacional - fazendo, às vezes, referência a existência de valores, padrões e "status" nestas instituições ${ }^{(18-19)}$.

A partir da década de 80 , são encontradas em periódicos estrangeiros da área da saúde, publicações que adotam essa temática sendo, em grande parte, trabalhos da área da enfermagem.

No levantamento realizado (1983-1993) foram encontradas 104 publicações com a temática cultura organizacional sendo 56 destas na área da enfermagem. É importante ressaltar que, nesta área constata-se um grande número de editoriais, comentários, resenhas, cartas, entre outras.

De maneira geral, estas publicações focalizam a importância da cultura na implementação de mudanças nas instituições de saúde.

A análise das características estruturais e históricas das instituições de saúde, bem como dos símbolos materiais, verbais e comportamentais é de fundamental importância na tentativa de solucionar problemas e implementar novos programas nestas instituições ${ }^{(20)}$. Algumas publicações analisam os aspectos conceituais ou modelos de cultura nas instituições de saúde ${ }^{(21-24)}$.

A cultura, enquanto um poderoso e sutil padrão de comportamento organizacional, pode facilitar ou dificultar a implementação de mudanças ${ }^{(21)}$.

Assim como nas organizações em geral não existe uma cultura única nas organizações de saúde podendo ser identificadas diferentes subculturas, como, por exemplo, a subcultura do "staff" administrativo, a subcultura dos médicos de um setor, entre outra ${ }^{(21)}$.

Alguns estudos organizacionais no campo da saúde adotam a abordagem etnográfica, ou analisando a cultura dos profissionais ${ }^{(25)}$ ou discutindo seus aspectos operacionais ${ }^{(26-27)}$.

No período 1993-1996 foram encontrados alguns estudos na área da enfermagem que tratam a organização sob o ponto de vista cultural e usam a etnografia como abordagem metodológica ${ }^{(28-}$ 32)

\section{CONSIDERAÇÕES FINAIS}

As reflexões aqui apresentadas remetem a algumas conclusões de natureza operacional, bem como de aplicabilidade dos resultados das pesquisas que adotam a cultura organizacional como tema de análise, na área da saúde, em geral, e da enfermagem, em particular.

Estudar a organização na sua dimensão antropológica pressupõe adotar uma das diferentes correntes da Antropologia. No entanto, a incorporação de alguns pressupostos de diferentes correntes pode também ser produtiva.

"raramente se encontra um antropólogo que se auto defina como estruturalista "stritu sensu" e algum que deixe de incluir "vários dos princípios do estruturalismo na sua prática"(33).

"Os rótulos(...) como, funcionalismo, estruturalfuncionalismo, neo-evolucionismo, interpretativismo, etc, do mesmo modo que todas as categorias totalizadoras, só simplificam e empobrecem o que é complexo, rico e enigmático"(33).

Assim, pode-se realizar etnografias menos focalizadas com a forma e mais abertas ao diálogo, porque é na "sensibilidade para o confronto ou o diálogo entre teorias acadêmicas e nativas que está o potencial de riqueza da antropologia"(33).

Ao elaborar o projeto de pesquisa deve-se reservar um espaço para mudanças, abrindo a possibilidade de redefinir o caminho a percorrer, a partir da própria experiência . Experiência que é única e imprevisível visto que se refere ao diálogo com o outro, à interação humana.

A experiência etnográfica é, certamente, transformadora, depende "da biografia do pesquisador" e das "imprevisíveis situações

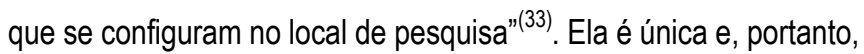
não há como traçar os passos que serão seguidos, sem o risco de ter que reconsiderá-los.

A etnografia utilizada nos estudos organizacionais deve ser considerada uma etnografia em andamento, pois sempre pode-se ter uma compreensão maior da complexidade da cultura caso o pesquisador possa permanecer por mais tempo entre os membros da cultura, aprendendo e validando símbolos e significados que emergem das interações.

A segunda reflexão refere-se à aplicabilidade dos resultados e, conseqüentemente, aos questionamentos: é a cultura "gerenciável"? Compreender a cultura de um grupo sempre pressupõe expectativa de mudança? Os estudos de cultura organizacional só 
têm sentido à medida que possam constituir-se em um instrumento da gerência para o estabelecimento de estratégias de intervenção?

Em primeiro lugar é importante ressaltar que a organização é uma cultura, organização são pessoas e as pessoas estão em contínua interação.

O homem é um ser ativo capaz de traçar sua trajetória no mundo social. É um ser de desejo, de pulsão, de relação e simbólico. "Ao mesmo tempo genérico e singular", "objeto e sujeito de sua ciência"(34).

Seu mundo é constituído de símbolos, significados, mitos, valores, crenças e rituais, construído através de suas interações sociais. Através da linguagem oral e escrita, verbal e não verbal; podemos decifrar esse universo simbólico que norteia suas ações nas relações sociais e no contexto organizacional.

A cultura organizacional é criada através das interações simbólicas do grupo, estabelecendo-se uma conduta coletiva, um universo simbólico. Esse universo simbólico serve de referência, norteia comportamentos, atitudes e ações. Analisar a cultura organizacional, nesta perspectiva, pressupõe decifrar como seus membros interpretam e compreendem suas experiências.

A compreensão da experiência humana e da realidade social pressupõe que o investigador coloque-se no lugar de quem a vivência, "usando seu quadro de referência", adotando abordagens metodológicas que permitem esse confronto de horizontes entre 0 pesquisador e pesquisados ${ }^{(34)}$. Algumas publicações analisam os aspectos conceituais ou modelos de cultura nas instituições de saúde ${ }^{(21-24)}$.

Assim, ao realizar uma etnografia é prudente que não se tenha a intenção primeira de que venha a constituir-se num instrumento para a gerência, no sentido de utilizar o conhecimento apreendido com os "nativos" em alguma causa própria ou de outrem. Ao invés disso, os dados etnográficos devem ser utilizados como instrumento de reflexão dos próprios sujeitos daquela subcultura.

Isso significa compreender a cultura como algo interno ao grupo e não manipulável. Ela é a própria organização, foi construída através de sua história, a história de seus membros. As mudanças ocorrem como parte ou reflexo de eventos internos. A mudança só ocorre a partir da mudança interna, de pessoas, de seres humanos em interação.

A utilização de "artifícios gerenciais" para criar ou mudar uma cultura organizacional resultaria na chamada "cultura artificial" ou "identidade dissimulada"(35). Adotar estratégias gerenciais para intervenção na cultura de uma organização é acreditar na cultura

\section{REFERÊNCIAS BIBLIOGRÁFICAS}

1. Lowenberg JS. Interpretive research methodology: broadening the dialogue. Adv Nurs Sci 1993; 2(16):57-69. como "um verniz" que pode ser retocado e nos gerentes como "estrategistas - fazedores" de valores. É acreditar que a cultura são apenas "palavras que designam componentes de uma cultura", que os mitos e ritos são "vividos mecanicamente" pelos seus membros e que seus "heróis não têm nada de sagrado".

A etnografia organizacional deve ser realizada com a crença de que possa vir a constituir-se num evento histórico naquela subcultura e com a convicção (ou esperança) de que, um certo informante, num certo momento de sua vida possa refletir sobre si ou sobre sua prática. E que esta reflexão tenha uma certa sintonia com o relato a seguir:

uma pesquisadora passou aqui mais de um ano buscando compreender o cotidiano da nossa subcultura e produziu uma etnografia que, nada mais é do que: somos nós falando de nós mesmos. É aquilo que sempre soubemos mais nunca dizemos uns para os outros. São coisas guardadas lá dentro que, às vezes, nem sabemos que sabemos. Ensiná-las nos permitiu, de certa forma, refletir sobre o nosso fazer (...). Essa etnografia, embora não fosse essa sua intenção, fez-me passar por um processo de transformação. Hoje eu compreendo mais que enfermeira eu sou e qual eu gostaria de ser, os meus valores e a dimensão do meu trabalho, a minha visão de homem e da natureza humana. Hoje eu sou um pouco diferente de ontem. Certamente essa nossa subcultura não será mais a mesma, desde que é criada, mantida e repassada através das minhas interações com os -outros, das nossas interações...Essa reflexão sobre nós mesmos nos tornou um pouco diferentes...

É importante ressaltar que, ao descrever a cultura organizacional devem ser omitidos alguns relatos, palavras, denúncias e posicionamentos frente a situações do cotidiano organizacional. Esta postura é mais do que simplesmente uma questão ética, na manutenção de sigilo ou anonimato dos informantes. Ela representa, a opção por uma descrição da subcultura para utilização, principalmente, interna, para reflexão de seus membros sobre os seus valores, mitos, suas estratégias de sobrevivência, seus medos e angústias, sobre a solidão e o compartilhar.

No entanto, a etnografia organizacional traz, também, contribuições no âmbito externo à subcultura estudada. Ela pode constituir-se em instrumento de reflexão dos enfermeiros em geral. Ela pode constituir-se numa "reflexão pedagógica", à medida que pode levar ao crescimento pessoal e profissional e então, assim, à mudanças. Não como uma estratégia de intervenção gerencial, mas como um evento natural da trajetória histórica de um grupo e de uma profissão.

2. Smircich $L$. Concepts of culture and organizational analysis. Adm Sci Q 1983; 28: 339-58.

3. Rodrigues SB. O chefinho, o telefone e "O BODE": autoritarismo e mudança cultural no Setor de Telecomunicações. [tese]. Belo Horizonte (MG): Faculdade de Ciências Econômicas/UFMG; 1991. 
4. Freitas ME. Cultura organizacional: formação, tipologias e impactos. São Paulo (SP): Makron/McGraw-Hill; 1991.

5. Morgan G. Paradigms, metaphors and puzzle solving in organization theory. Adm Sci Q 1980; (25): 605-22.

6. Goffman E. The presentation of self in everyday life. New York (NY): Doubleday; 1959.

7. Managham IL, Overington MA. Dramatism and the theatrical metaphor: really playing and critical distances In: Morgan G., (ed). Beyond method: social research strategies. Baverly Hills (CA): Sage;1983.

8. Fleury MTL. Cultura organizacional: os modismos, as pesquisas, as intervenções uma discussão metodológica. Rev Adm Emp 1989; 24(1): 3-9.

9. Sanday PR. The ethnographic paradigm (s). Adm Sci Q 1979; 24:527-38.

10. Benedict R Patterns of culture. New York: Houghton Mifflin; 1934. 11. Mead M. Coming of age in Samoa. New York: New Americam Library Mentor Books; 1949.

12. Malinowski B. Argonauts of the western pacific. New York: Dutton; 1950.

13. Radcliffe-Brown AR. Struture and function in primitive society. London: Oxford University Press; 1952.

14. Goodenough W. Description and comparison in cultural Anthropology. Chicago: Aldine; 1970.

15. Geertz C. A interpretação das culturas. Rio de Janeiro (RJ): Guanabara; 1989.

16. Berger $P$, Luckmann T. Construção social da realidade: tratado de sociologia do conhecimento. $6^{\text {a }}$ ed. Petrópolis (RJ): Vozes; 1985. 17. Spradley J. The ethnographic interview. New York: Holt Rinehart \& Winston; 1979.

18. Ribeiro ABC. Administração de pessoal nos hospitais. $2^{a}$ ed. São Paulo (SP): LTR; 1977.

19. Gonçalves EL. O hospital e a visão administrativa contemporânea. São Paulo (SP): Pioneira; 1983.

20. Hughes L. Assessing organization culture; strategies for the external consultant. Nurs Forum 1990; 25(1):15-9.
21. Coeling HVE, Simms LM. Facilitating innovation at the nursing unit level through cultural assessment. Part. 1: how to keep management ideas from falling on deaf ears. J Nurs Adm 1993a; 23(4):46-53.

22. Del Bueno DJ, Vincent PM. Organizational culture: how important is it? J Nurs Adm 1986; 16(10):15-20.

23. Glazner L. Understanding corporate culture: use of systems theory. AAOHN 1992; 40(8): 383-7.

24. Coeling HVE, Simms LM. Faciliting innovation at the unit level through cultural assessment. Part. 2: adapting managerial ideas to the unit work group. J Nurs Adm 1993b; 23(5):13-20.

25. Nijsmans M. Professional culture and organizational morality: an ethnographic account of a therapeutic organization. Br J Soc 1991; 42(1):1-19.

26. Schmoll BJ. Ethnographic inquiry in clinical settings. Phys Ther 1987; 67(12): 1895-7.

27. Townsend EA. Institutional ethnography: explicating the social organization of professional health practices intending client empowerment. Can J Public Health 1992; 83(1): 58-61.

28. Boddy J. An ethnography of caring and control in an acute psychiatric unit. Nurs Prax N Z 1993; 8(1): 43.

29. Holland CK. An ethographic study of nursing culture as an esploration for determining the existence os a system of ritual. J Adv Nurs 1993; 18(9): 1461-70.

30. Henderson A. The significance for critical care nurses of the "dying with dignity" legislation. Aust Crit Care 1994; 7(2): 23-6.

31. Chase SK. The social context of critical care clinical judgment. Heart Lung 1995; 24(2): 154-62.

32. Peixoto MRB. A prioridade, o isolamento e as emoções: estudo etnográfico do processo de socialização em um centro de tratamento intensivo. [tese] São Paulo (SP): Escola de Enfermagem/USP; 1996. 33. Peirano M. A favor da etnografia. Rio de Janeiro (RJ): RelumeDumará; 1995.

34. Chanlat JF, coordenador. O indivíduo na organização: dimensões esquecidas. São Paulo (SP): Atlas; 1992.

35. Chanlat JF, coordenador. O indivíduo na organização: dimensões esquecidas. São Paulo (SP): Atlas; 1994. 